\title{
Preparing educators for work in an inclusive educational environment of a preschool educational organization
}

\author{
O.N. Rodionova ${ }^{1 *}$, L.L. Denisova ${ }^{2}$, and E.N. Ovcharenko ${ }^{3}$ \\ ${ }^{1}$ Federal State Budgetary Educational institution of higher education "Armavir State Pedagogical \\ University", Armavir, Russia \\ ${ }^{2}$ Federal State Budgetary Educational institution of higher education "Armavir State Pedagogical \\ University", Armavir, Russia \\ ${ }^{3}$ Federal State Budgetary Educational institution of higher education "Armavir State Pedagogical \\ University", Armavir, Russia
}

\begin{abstract}
The article considered the essence of training educators to work in an inclusive educational environment of a preschool educational organization. The problems and contradictions of inclusive practice in the conditions of a preschool educational organization are considered, which is confirmed by a SWOT-analysis of the educational activities of a preschool educational organization in conditions of inclusion. This method is one of the most effective and promising methods of scientific-analytical and reflective research, which is especially important in the framework of pedagogical science. The authors reveal the content of the components of the readiness of educators to implement inclusive practice in a preschool educational organization. In addition, a significant segment of the research is devoted to the consideration of the structure, components and levels of readiness of educators to work in an inclusive educational environment of a preschool educational organization. Based on this, an exhaustive conclusion is made, which is reflected in the final part of the article.
\end{abstract}

\section{A problem statement}

The preschool education system is currently characterized by significant transformations, in accordance with which the problems of educational inclusion are being actualized, providing equal access to preschool education services, including for children with disabilities. At the present stage, educational inclusion is considered as a means of social rehabilitation of preschool children with disabilities and their families. In addition, the development of inclusive preschool education provides equal rights and the opportunity to choose an individual educational route for any child, regardless of his physical and other characteristics.

\footnotetext{
* Corresponding author: prof-ped.gpa@mail.ru
} 
This initiates a number of problematic issues related to the insufficient competence of teachers in the implementation of modern technologies of inclusive practice; low awareness of educators about modern forms of interaction with parents; low motivation of parents for purposeful cooperation with a preschool educational organization in this area.

Preparing teachers of preschool educational organizations for the implementation of inclusive practice in the system of preschool education will allow realizing the potential of effective polysubjective interaction of preschoolers with disabilities with significant adults and peers. Based on this, it would be fair to designate this thesis as a key research problem.

\subsection{The objective of the work}

The practice of implementing inclusive education at the level of preschool education, the interaction of "special" and ordinary children in an inclusive educational space is presented in the works of foreign and Russian researchers J. Goodman, M. Hazelkorn, J. Bucholz, M.L. Duffy, Y. Kitta, H. Warming, M. Koster, M.E. Timmerman, H. Nakken, S.J. Pijl, E.J. van Houten; L.S. Soodak; I.V. Vachkov and others.

And the issues of professional training, retraining and advanced training of teachers, special teachers (teachers-defectologists), educational psychologists for work in inclusive education are presented in the works of J.-R. Kim; K. Scorgie; A. De Boer, S.J. Pijl, A. Minnaert; E.-E. Kourkoutas, M.-R. Xavier; A. Moran; S.V. Alekhina; D.Z. Akhmetova, M.M. Bezrukikh, O.A. Denisova; E.N. Kutepova, E.A. Martynova. V.N. Ponikarova, N.A. Romanovich and others.

Many researchers reveal the essence of the concept of "inclusive competence" (M.Yu. Aibazova, K.Yu. Lavrinets, I.N. Khafizullina), as well as methodological and methodological approaches to its formation among future teachers B. Cagran, M. Schmidt; N.K. French, R.V. Chopra, L. Florian; H. Linklater; A.V. Vinevskaya, O.V. Vorobyova, M.Yu. Denisova, A.D. Goneev and E.G. Samartseva, E.S. Slyusareva, V.V. Tricky and others.

\section{Results of the research}

According to the requirements of the Federal State Educational Standard of Preschool Education (2013), an educator in a preschool educational organization is the subject of correctional work and inclusive education, ensuring the diversified development of children, taking into account age and individual characteristics and special educational needs, social adaptation.

We share the position of the researcher V.V. Hitruk that the professional activity of a teacher in an inclusive education cannot be effective without an inclusive readiness formed in him. In her opinion. Inclusive readiness of a teacher is an integral quality of the subject of professional pedagogical activity and a component of his professional readiness, meaningfully revealed through a set of competencies and predetermining professional choice, orientation (orientation), behavioral and communicative strategies, methods of professional pedagogical activity in the current conditions of inclusive education [1].

Our study involved teachers of the preschool educational organization of the municipal autonomous preschool educational institution No. 37 in the city of Armavir, Krasnodar Territory. The staff of the preschool educational organization has tested the educational project «Psychological and pedagogical support of preschool children in the conditions of inclusive education» [2].

Anticipating the work on the implementation of this project, we studied the possibilities, advantages, risks of an inclusive process launched by a preschool educational organization. 
For this, a SWOT analysis of the educational activities of teachers of a preschool educational organization in the conditions of inclusive practice was undertaken, which makes it possible to identify:

- strengths and weaknesses of a preschool educational organization, potentially dangerous situations that can be encountered in the educational services market;

- to determine the possibilities of preventing negative factors in the development of a preschool educational organization in the conditions of inclusive practice. You can see the results in table 1, which presents SWOT analysis of the educational activities of teachers of a preschool educational organization in the conditions of inclusive practice (Table 1).

Table 1. SWOT analysis of the educational activities of teachers of a preschool educational organization in the conditions of inclusive practice.

\begin{tabular}{|c|c|}
\hline $\begin{array}{c}\text { Opportunities (favorable factors } \\
\text { external environment) }\end{array}$ & $\begin{array}{c}\text { Strength (advantages of a preschool } \\
\text { educational organization) }\end{array}$ \\
\hline $\begin{array}{l}\text { In the microdistrict, the preschool organization } \\
\text { is the only and conveniently located (rich } \\
\text { infrastructure of the microdistrict). }\end{array}$ & $\begin{array}{l}\text { Equal access to education for all pupils, taking } \\
\text { into account special educational needs and } \\
\text { individual opportunities in a variety of } \\
\text { organizational forms of integration and inclusive } \\
\text { practice. } \\
\text { Support and facilitation of a personality- } \\
\text { oriented trajectory of development of preschool } \\
\text { children with disabilities in the context of } \\
\text { effective polysubject interaction with significant } \\
\text { adults and children. }\end{array}$ \\
\hline $\begin{array}{l}\text { Demand for a wide range of educational } \\
\text { services for preschool children, including those } \\
\text { with disabilities. }\end{array}$ & $\begin{array}{l}\text { Variable subject-spatial developmental } \\
\text { environment of a preschool institution; } \\
\text { High satisfaction of parents of pupils with the } \\
\text { quality of educational services. }\end{array}$ \\
\hline $\begin{array}{l}\text { The favorable reputation of the preschool } \\
\text { educational organization in society, a bright and } \\
\text { positive image, the presence of professional } \\
\text { awards. }\end{array}$ & $\begin{array}{l}70 \% \text { or more of teachers of the first and highest } \\
\text { category. } \\
\text { High rating assessment of the activities of a } \\
\text { preschool educational organization in the city's } \\
\text { preschool education system. } \\
\text { Favorable psychological climate in a preschool } \\
\text { educational organization. }\end{array}$ \\
\hline $\begin{array}{l}\text { Updating the practice of inclusive education in } \\
\text { society, ensuring equal accessibility of } \\
\text { preschool education services for children. }\end{array}$ & $\begin{array}{l}\text { Extensive practical experience in educational } \\
\text { and correctional development activities of } \\
\text { teachers. }\end{array}$ \\
\hline $\begin{array}{l}\text { A variety of business and creative relationships } \\
\text { with various organizations and institutions of } \\
\text { the city. }\end{array}$ & $\begin{array}{l}\text { High efficiency of participation of pupils and } \\
\text { employees of a preschool educational } \\
\text { organization in events of various levels. }\end{array}$ \\
\hline $\begin{array}{c}\text { Threats (opposition of the external } \\
\text { environment) }\end{array}$ & $\begin{array}{c}\text { Weakness (shortcomings of the preschool } \\
\text { educational organization) }\end{array}$ \\
\hline $\begin{array}{l}\text { Lack of effective interaction between different } \\
\text { regulators of inclusive education: family, } \\
\text { preschool educational organization, external } \\
\text { environment. }\end{array}$ & $\begin{array}{l}\text { The lack of a clear formulation of the goals of } \\
\text { managing inclusive education in a preschool } \\
\text { educational organization and its accessibility to } \\
\text { the understanding of parents. }\end{array}$ \\
\hline $\begin{array}{l}\text { Low motivation of parents for targeted } \\
\text { cooperation with an educational institution in } \\
\text { this area. }\end{array}$ & $\begin{array}{l}\text { Low awareness of teachers about modern forms } \\
\text { of interaction with parents in the context of } \\
\text { inclusive education of preschoolers in a } \\
\text { preschool educational organization. }\end{array}$ \\
\hline $\begin{array}{l}\text { Autism in relationships and deficiency of } \\
\text { cognitive functions, as well as individual }\end{array}$ & $\begin{array}{l}\text { Insufficient competence of teachers in modern } \\
\text { technologies of psychological and pedagogical }\end{array}$ \\
\hline
\end{tabular}


psychological and personal characteristics of children with disabilities. support of preschoolers in an inclusive practice. Lack of technological support for psychological and pedagogical support of preschool children for the implementation of inclusion, including the technology of tutor support for children with disabilities.

The results of a SWOT-analysis of the educational activities of teachers of a preschool educational organization in the context of inclusive practice shows the need to form and improve the readiness of educators to work in an inclusive educational environment.

Based on the existing ideas about readiness for various aspects of professional activity, it seems to us possible to determine the structure of educators readiness to work in an inclusive educational environment of a preschool educational organization. It includes the following components: motivational-value, theoretical, practical, evaluative, creative, affective.

We have determined the structure of the components of the readiness of educators to work in an inclusive educational environment of a preschool educational organization, their components, criteria and signs of expression. The main content of the components we have highlighted is as follows:

1. Motivational value. the component assumes the presence of a positive attitude, interests, needs, in the aggregate, providing stable motivation of educators to work in an inclusive educational environment of a preschool educational organization Its axiological aspect is associated with the problems of value comprehension of the personality of children, including those with disabilities and the importance of inclusive education. It consists of two components:

a) motivational, characterized by such indicators-signs as interest in educational inclusion, the need to study inclusive practice, the need to increase knowledge about inclusion, the motives of professional activity in an inclusive process, etc.

The generalized criterion of its severity is the formation of motives and needs in the implementation of knowledge in pedagogical activity in the conditions of inclusive education.

b) value (axiological), the main indicator of which is the recognition of the importance of the values of educational inclusion, etc.

The criterion for the formation of readiness is the awareness of the universal human value of inclusive education, value comprehension of the personality of children, including those with disabilities.

2. The theoretical (cognitive) component helps to organize information on a single conceptual basis, in a single logic. It provides for mastering not only a certain level of knowledge, but also the formation of the teacher's outlook, as well as the possibility of their constant replenishment and renewal. This component is determined by the professional and pedagogical orientation, which is the leading motive of the cognitive activity of educators in this area.

The main indicators of this are knowledge: theoretical, methodological, methodological, technological; features of inclusive processes; foundations for the development of modern inclusive education, etc.; manifestation of cognitive activity in this area. The criteria for the formation of the theoretical component were determined: erudition and awareness in the field of theory and practice of inclusive education.

3. The practical (procedural-activity) component provides a direct solution to theoretical and practical problems, the design of new learning goals, principles, pedagogical technologies. The ability to use new pedagogical technologies, means, methods, techniques allows you to build individual routes of education and upbringing, taking into account the 
needs and needs of the personality of children with disabilities. It consists of procedural and operational components:

a) procedural (professional component of pedagogical activity in the conditions of inclusive practice) includes the following indicators of skills: to conduct a dialogue; organize interaction; to carry out the pedagogical process in the conditions of an inclusive educational environment of a preschool educational organization, etc. Criteria for its manifestation: the organization of productive pedagogical communication with children with disabilities; the ability to carry out pedagogical activities in an inclusive educational environment.

b) the operational (methodological component) is characterized by indicators of skills in the field of inclusive education: organizational, communicative, perceptual, prognostic, projective, etc. The criterion for the formation of this component is the ability to select adequate methodological means in teaching and upbringing in a multi-subject group of preschoolers.

4. The evaluative component performs a reflexive-regulatory function. It is determined by the "inclusive competence" and the general culture of the personality of the educator and involves the determination of specific directions for self-improvement of the individual, the actualization of the internal forces of his self-development and makes it possible to diagnose his own qualities and properties and, on the basis of drawing up a self-portrait, to correct and build a professional image.

The evaluative component includes three components: diagnostic, reflective, corrective. Diagnostic characteristics are characterized by the following signs: assessment, selfassessment and self-analysis of activities in an inclusive educational environment of a preschool educational organization. Reflexive - awareness and understanding of their professional activities. Its criteria are - awareness of the importance of inclusive competence in teaching and upbringing of preschoolers. Corrective - manifested in the possession of methods of correction in the process of interaction.

5. The creative (creative) component contains the following features: the presence of elements of creative thinking, creative imagination, the inclusion of elements of inclusion in professional creativity; creative self-development, co-creation; implementation of the incentive function. Its criterion is a creative approach to work in an inclusive educational environment of a preschool educational organization.

6. The affective component includes an emotional and sensory component, the indicators of which are the manifestation of positive and negative emotions when meeting with; positive emotions (feeling of empathy), negative; empathic (the desire to change one's own point of view, the relativization of views on inclusive education).

The criterion for the formation of a component is the experience of an emotional and empathic attitude towards children with disabilities.

The selected components in ensuring the readiness of the educator to work for work in an inclusive educational environment of a preschool educational organization perform the following main functions: personality-developmental, cognitive and social-cognitive, procedural, evaluative, reflexive-corrective, etc.

Note that the totality of these components of readiness does not pretend to fully characterize this process. Each of them is determined by the corresponding structure of the educator's pedagogical consciousness, his pedagogical skills, personal orientations and represent an integral system capable of coordinating the process of forming the educator's knowledge and skills in unity with the pedagogical culture of his personality.

Based on the study of the professional activity of the educator in the inclusive educational environment of the preschool educational organization, as well as the identified components of the professional and pedagogical readiness, the levels of the formation of 
the teacher's readiness to work in the inclusive educational environment of the preschool educational organization were determined.

In terms of content, the levels of formation of the teacher's readiness to work in an inclusive educational environment of a preschool educational organization can be interpreted as follows:

- teachers with a high level of readiness to work in an inclusive educational environment of a preschool educational organization are distinguished by a high degree of awareness in the field of inclusive education, the ability to establish contact with children and significant adults, a high communicative self-control in communication, a high degree of possession of emotional etiquette, non-verbal means of communication; the ability to manage their emotional state in the process of polysubject interaction; assertiveness in communication; a high degree of performance, striving for creative improvement and professional excellence;

- the average level of readiness to work in an inclusive educational environment of a preschool educational organization is typical for teachers who have a partial formation and unsystematic knowledge in the field of inclusive education, a partial level of skills in this area. For teachers of this category, the inability to apply them in the situation of pedagogical interaction (communication) is also characteristic; inability to manage their emotional state in the context of interaction; educators have elements of communicative self-control in communication;

- teachers with a low level of readiness to work in an inclusive educational environment of a preschool educational organization experience the same communication difficulties as teachers with an average level of formation, but are more categorical in the perception and assessment of children; show negative motives for studying inclusive education, they have a lack of readiness and ability to dialogue, lack of ownership of emotional and etiquette culture in interaction, low communicative self-control in communication.

To confirm the stated assumptions, a questionnaire was developed for teachers, aimed at identifying the initial level of readiness of educators to work in an inclusive educational environment of a preschool educational organization according to the criteria and indicators presented above.

The results of the questionnaire allow us to conclude that at the beginning, in the level indicators of the readiness of educators to work in an inclusive educational environment of a preschool educational organization, the following picture is observed: a high level of readiness to work in an inclusive educational environment of a preschool educational organization - in $23.5 \%$ of teachers, average - in $50,6 \%$ of teachers, low - in $25.9 \%$ of teachers.

Further training of teachers to work in an inclusive educational environment of a preschool educational organization provided the dynamics of level movements of teachers' readiness to work in an inclusive educational environment of a preschool educational organization.

\section{Conclusions}

The organization of inclusive practice ensured the achievement of the modern quality of the educational services provided by the teaching staff, the results of the socialization of children, including children with disabilities. The development, testing and implementation of a system for training educators to work in an inclusive educational environment of a preschool educational organization contributed to an increase in the efficiency of the process of diagnostics, forecasting, correction and integration of children with disabilities into the environment of their peers.

The mastering of modern technologies of inclusive education by teachers has created the basis for the formation of educators' readiness to work in an inclusive educational 
environment of a preschool educational organization and the necessary professional competencies, increases competitiveness.

The creation by educators of psychological and pedagogical conditions for effective polysubjective interaction of preschoolers with disabilities with significant adults and peers made it possible to identify and evaluate the corresponding range of changes in the child's socialization process, served as a guideline for optimizing the work of a preschool educational organization in an inclusive practice.

A variety of business and creative ties of a preschool educational organization with various organizations and institutions of the city, the development of forms, means and methods of interactive interaction of teachers with parents of pupils in an inclusive practice has increased the motivation of parents for targeted cooperation in this area.

\section{References}

1. V.V. Hitruk, Formation of inclusive readiness of future teachers in the context of higher education, 390 (2015)

2. I.U. Lebedenko, O.N. Rodionova, Inclusive education of preschool children: organizational aspect, Bulletin of the Volgograd State Pedagogical University, 8, 20 25 (2015)

3. N.N. Malofeev, Correction, integration, inclusion, what's next?, Special Education: Proceedings of the XI International Scientific Conference, 1, 9-15 (2015)

4. N.M. Nazarova, On the problem of developing theoretical and methodological foundations of educational integration, Psychological Science and Education, 3, 5-11 (2011)

5. S.V. Alehina, Organization of special educational conditions for children with disabilities in educational institutions: guidelines, 92 (2012)

6. M.U. Aybazova, Preparing future teachers to work in inclusive education, Pedagogy, 4, 82-86 (2014)

7. S.V. Alehina, M.M. Semago, Creation and testing of a model of psychological and pedagogical support of inclusive practice, 156 (2012)

8. S.V. Alehina, Inclusive education and teacher psychological readiness, Bulletin of MGPPU, Series "Pedagogy and Psychology", 4, 118-127 (2012)

9. I.V. Vachkov, Model of the formation of a positive attitude towards younger schoolchildren with disabilities among their peers, Psychological Science and Education, 3, 59-65 (2011)

10. O.A. Denisova, Training of teaching staff for the implementation of inclusive education, Bulletin of the Cherepovets State University, 4, 109-112 (2012)

11. B. Cagran, M. Schmidt, Attitudes of Slovene teachers towards the inclusion of pupils with different types of special needs in primary school, Educational Studies, 2, 171195 (2011)

12. I.A. Zimnuya, Competence-based approach in education (methodological and theoretical aspect), Problems of the quality of education, Materials of the XIV AllRussian meeting, 2, 6-12 (2004)

13. J.-R Kim, Influence of teacher preparation programmes on preservice teachers' attitudes toward inclusion, International Journal of Inclusive Education, 3, 355-377 (2011) 
14. V.N. Ponikarova, Diagnostics of readiness to carry out pedagogical activity in integrated / inclusive education, Bulletin of the Cherepovets State University. A.S. Pushkin, 1, 130-133 (2013)

15. F. Polat, Inclusion in education: A step towards social justice, International Journal of Educational Development, 1, 50-58 (2011)

16. Susan J. Peters, Inclusive Education OVZ: Strategies for All Children, 124 (2010)

17. C.L. Salisbury, M.M. Palombaro, W.M. Hollowood, On the nature and change of an inclusive elementary school, The Journal of the Association for Persons with Severe Handicaps, 18, 75-84 (1993)

18. V.V. Hitruk, The teacher's readiness to work in inclusive education through the prism of a complex of competencies, Bulletin of Smolensk State University, 4, 446-459 (2013)

19. I.N. Hafizulina, Formation of inclusive competence of future teachers in the process of professional training, 213 (2008)

20. Y.V. Shumilovskaya, Preparing the future teacher to work with students in an inclusive education, 175 (2011) 